\title{
HPV Vaccination among Adolescent Males: Results from the National Immunization Survey-Teen
}

\author{
Paul L. Reiter, PhD ${ }^{1,2}$, Melissa B. Gilkey, $\mathrm{PhD}^{3}$, and Noel T. Brewer, $\mathrm{PhD}^{3,4}$ \\ ${ }^{1}$ Division of Cancer Prevention and Control, College of Medicine, The Ohio State University, \\ Columbus, $\mathrm{OH}$ \\ ${ }^{2}$ Comprehensive Cancer Center, The Ohio State University, Columbus, $\mathrm{OH}$ \\ ${ }^{3}$ Lineberger Comprehensive Cancer Center, Chapel Hill, NC \\ ${ }^{4}$ UNC Gillings School of Global Public Health, Chapel Hill, NC
}

\begin{abstract}
US guidelines provided a permissive recommendation forHPV vaccine for males in 2009, with an updated recommendation for routine vaccination in 2011. Dataon vaccine uptake among males, however, remain sparse. We analyzed 2010-2011 data (collected mostlyprior to the recommendation for routine vaccination) from the National Immunization Survey-Teen for a nationally representative sample of adolescent males ages 13-17 ( $n=22,365)$. We examined HPV vaccine initiation( receipt of at least one doseba sed on healthcare provider records) as the primary outcome. Analyses used weighted logistic regression. HPV vaccine initiation increased from $1.4 \%$ in 2010 to $8.3 \%$ in 2011. Parents who reported receiving a healthcare provider recommendation to get their sons HPV vaccine were much more likely to have vaccinated sons ( $\mathrm{OR}=19.02,95 \% \mathrm{CI}$ : 14.36-25.19). Initiation was also higher among sons who were Hispanic (OR=1.83, 95\% CI: 1.24 2.71) or who were eligible for the Vaccines for Children program ( $\mathrm{OR}=1.53,95 \%$ CI: 1.01-2.31). Only31.0\% of parents with unvaccinated sons indicatedtheir sons were "somewhat likely" or "very likely" to receive HPV vaccine in the next year. The most common main reasons for parents not intending to vaccinate were believing vaccination is not needed or not necessary (24.5\%), not having received a provider recommendation (22.1\%), and lack of knowledge (15.9\%). HPV vaccination is low among adolescent males in the US, and provider recommendation for vaccination is likely keyto improv ingvaccine uptake. Given the updated recommendation for routine vaccination and the changes in health insurance coverage that are likely to follow, continued efforts are needed to monitor HPV vaccination among males.
\end{abstract}

\footnotetext{
(C) 2013 Elsevier Ltd. All rights reserved.

Correspondence and requests for reprints should be sent to: Paul L. Reiter, PhD, Division of Cancer Prevention and Control, College of Medicine, The Ohio State University, 1590 North High Street, Suite 525, Columbus, Ohio 43201, 614-366-4265 (phone); 614-293-5611 (fax), Paul.Reiter@osumc.edu.

Conflict of Interest

PLR and NTB have received research grants from Merck Sharp \& Dohme Corp. NTB has also received grants from GlaxoSmithKline and served on paid advisory boards and served as a paid speaker for Merck Sharp \& Dohme Corp. These funds were not used to support this research. MBG has no conflicts of interest to disclose.

Publisher's Disclaimer: This is a PDF file of an unedited manuscript that has been accepted for publication. As a service to our customers we are providing this early version of the manuscript. The manuscript will undergo copyediting, typesetting, and review of the resulting proof before it is published in its final citable form. Please note that during the production process errors may be discovered which could affect the content, and all legal disclaimers that apply to the journal pertain.
} 


\section{Keywords}

HPV; HPV vaccine; Males; NIS-Teen; Adolescent Health

\section{Introduction}

Human papillomavirus (HPV) vaccine offers important health benefits for males.

Quadrivalent HPV vaccine against types 6, 11, 16, and 18 is currently approved by the Food and Drug Administration (FDA) to prevent genital warts and anal cancer in males [1].

Genital warts are caused primarily by types 6 and 11 [2], and anal cancer is caused primarily by types 16 and 18 [3]. About $4 \%$ of adult males report a prior diagnosis of genital warts [4], and over 2,000 incident cases of anal cancer occur annually among males [5]. Administering HPV vaccine to males may also have indirect health benefits for their female partners [6] due to the high HPV concordance levels among sexual partners [7].

HPV vaccine received its first national recommendation for males in the US in October 2009 [8]. At that time, the Advisory Committee on Immunization Practices (ACIP) provided a permissive recommendation for administering the three-dose series of quadrivalent vaccine [8]. The permissive recommendation allowed the vaccine to be administered to males ages 9-26 but did not make it part of their routine vaccination schedule. The ACIP strengthened its recommendation in October 2011 by recommending routine HPV vaccination for males ages 11-12 with catch-up vaccination for males ages 13-21 [9]. The updated recommendation still allows the vaccine to be given to males as young as age 9 and through age 26 [9].

Under the permissive recommendation, someprivate health insurance plans covered HPV vaccine for males, as did the Vaccines for Children (VFC) program [10]. The VFC program is a federal program that provides vaccines free of charge to children who might not otherwise be vaccinated because of inability to pay [11]. A child is eligible for the VFC program if he or she is less than 19 years old and is American Indian or Alaska native, Medicaid-eligible, uninsured, or underinsured (i.e., insurance does not cover vaccines, does not cover certain vaccines, or covers vaccines but has a fixed dollar limit or cap for coverage [after which the child becomes eligible for the VFC program]). Underinsured children are eligible to receive vaccines only at Federally Qualified Health Centers or Rural Health Clinics. It is not yet entirely clear how the updated recommendation for routine HPV vaccination for males has affected insurance coverage of the vaccine by private health insurance plans, though it is likely that insurance coverage has increased.

Limited data exist on HPV vaccine uptake among males in the US. Initial estimates found that only about $2 \%$ of adolescent males had received any HPV vaccine doses by the end of 2010 [12-14], with a slight increase to about $8 \%$ by the end of 2011 [15,16]. Although several studies have examined correlates of HPV vaccine uptake among adolescent females [17] and vaccine acceptability for males [14,18-25], only a few studies have identified correlates of HPV vaccine uptake among adolescent males and reasons why parents are not vaccinating their sons $[13,16,26,27]$. We analyzed provider-verified vaccination data from a nationally representative sample of adolescent males to provide insight into HPV vaccine uptake among males. 


\section{Material and Methods}

\section{Study Design}

We used publicly available data from the National Immunization Survey-Teen (NIS-Teen) $[28,29]$, an annual survey conducted by the Centers for Disease Control and Prevention (CDC) to monitor vaccination among 13-17 year-olds. The NIS-Teen methodology has been previously described in great detail [30]. The CDC conducts the NIS-Teen in all 50 states, the District of Columbia, and selected local areas. The NIS-Teen is an add-on to the National Immunization Survey (NIS), which examines vaccination among children 19-35 months old. Data collection for the NIS-Teen involves two phases: 1) a random-digit-dialed (RDD) telephone survey with parents/guardians (referred to as "parents") of adolescents ages 13-17; and 2) a mailed survey to adolescents' healthcare providers identified by parents and for whom consent to contact is obtained. Vaccination estimates are based on data obtained from provider records $[12,15]$. The CDC uses a complex stratified sampling strategy for the NIS-Teen to obtain a national probability sample of adolescents ages 13-17. For 2010, the RDD sampling frame consisted of only landline telephones, whereas 2011 was also able to account for cellular telephones [31,32]. The 2011 NIS-Teen dual-frame sampling approach used independent RDD samples from landline and cellular sampling frames [32]. If a selected household contains more than one adolescent ages 13-17, one index adolescent is randomly chosen for the NIS-Teen.

We examined NIS-Teen data from 2010-2011 (all years with HPV vaccination data for males at the time of analyses) for adolescents with provider-verified vaccination records. Most data were collected prior to the ACIP providing their recommendation for routine administration of HPV vaccine to males in October 2011. Datasets included 19,257 adolescents from 2010 (excluding US Virgin Islands; household response rate $=58.0 \%$ [12]) and 23,564 adolescents from 2011 (excluding US Virgin Islands; household response rate $=57.2 \%$ for landline households and $22.4 \%$ for cellular households [15]). We report data on 22,365 adolescent males with provider-verified vaccination records. Data collection for the NIS-Teen was approved by the National Center for Health Statistics Research Ethics Review Board. Analysis of deidentified data from the survey is exempt from the federal regulations for the protection of human research participants. The Institutional Review Board at The Ohio State University determined this study was exempt from review.

\section{Measures}

HPV vaccination status was determined using data from provider-verified vaccination records. We examined HPV vaccine initiation (receipt of at least one dose of HPV vaccine) as the primary outcome variable. We focused on initiation because few males have received any doses of HPV vaccine $[15,16,26]$ and initiation is an appropriate outcome for new health behaviors [33]. We did, however, characterize HPV vaccine completion (receipt of all three doses) for descriptive purposes.

Among parents of unvaccinated sons, we examined intent to get their sons HPV vaccine in the next year. Surveys assessed intent by asking, "How likely is it that [TEEN] will receive HPV shots in the next 12 months?" Response options included "not likely at all," "not too likely," "not sure/don't know," "somewhat likely," and "very likely" (coded 1-5). Parents who indicated one of the first three responses were then asked, "What is the main reason [TEEN] will not receive HPV shots in the next 12 months?" This open-ended item allowed parents to indicate multiple reasons, which the CDC coded into categories.

Surveys assessed various demographic characteristics (Table 1), which included information about the son, mother, and household. If someone other than the mother completed the parent survey, this individual provided information about the mother. Parents provided data 
on health-related characteristics, including whether their sons had visited a healthcare provider in the last year and their sons' healthcare coverage. We examined whether sons were eligible for the VFC program. Surveys also assessed whether parents had ever heard of HPV and HPV vaccine and if they had ever received a healthcare provider recommendation to get their sons HPV vaccine.

\section{Data Analysis}

We calculated descriptive statistics for HPV vaccine initiation, completion, parents' intent to get their sons HPV vaccine in the next year, and parents' main reasons for not intending to vaccinate. We used logistic regression to identify correlates of HPV vaccine initiation, entering all statistically significant bivariate correlates $(p<0.05)$ into a multivariate logistic regression model. We constructed two multivariate models: 1) one that included whether parents had received a healthcare provider recommendation to get their sons HPV vaccine; and 2) one that excluded provider recommendation. We constructed the latter model in accordance with previous analyses of NIS-Teen data on HPV vaccination among adolescent females [34]. Both multivariate models controlled for state of residence to account for unmeasured factors between states that may be important to HPV vaccination. Multivariate models produced adjusted odds ratios (ORs) and 95\% confidence intervals (CIs). We did not examine parents' awareness of HPV and HPV vaccine as predictors of vaccination, because for some parents awareness was likely due to a healthcare provider's recommendation or actual vaccination, while for others awareness preceded the provider interaction.

Analyses used sampling weights in determining proportions and effect estimates to account for the complex design of the NIS-Teen [31,32]. Frequencies are not weighted. We recoded responses of "don't know" and "refused" to missing (unless otherwise noted) and excluded these responses from analyses. Statistical tests were two-tailed with a critical alpha of 0.05 . We used SAS Version 9.2 (Cary, NC) to conduct analyses, including procedures for analyzing survey data (e.g., PROC SURVEYLOGISTIC). We followed recommended methods for combining multiple years of NIS-Teen data [32].

\section{Results}

\section{Participant Characteristics}

The age distribution was fairly even among sons, with each age having at least $19.1 \%$ of the total sample (Table 1). Over half (58.6\%) of sons were non-Hispanic white. Most mothers were 35 years of age or older (90.7\%), had at least some college education (60.0\%), and were married (70.2\%). A majority of parents had heard of HPV (78.8\%) and HPV vaccine $(82.0 \%)$, but only $9.9 \%$ had received a healthcare provider recommendation to get their sons HPV vaccine.

\section{HPV Vaccination}

For 2010-2011 combined, 4.9\% of adolescent males had initiated the HPV vaccine regimen (Table 2). Only $0.7 \%$ of sons had completed the three-dose regimen. HPV vaccine initiation increased from $1.4 \%$ in 2010 to $8.3 \%$ in 2011 . All variables were correlated with vaccine initiation in bivariate analyses (Table 2).

In multivariate analyses, healthcare provider recommendation was the strongest correlate of HPV vaccine initiation (Table 3). Parents who reported receiving a healthcare provider recommendation to get their sons HPV vaccine were much more likely to have vaccinated sons (OR=19.02, 95\% CI: 14.36-25.19). Initiation was also higher among sons who were Hispanic (compared to non-Hispanic white sons; OR=1.83, 95\% CI: 1.24-2.71), whose health insurance coverage was not through their parents' employers or unions (compared to 
sons whose health insurance coverage was through their parents' employers or unions; $\mathrm{OR}=1.6195 \%$ CI: $1.08-2.40)$, or who were eligible for the VFC program (OR=1.53, 95\% CI: 1.01-2.31). Lastly, the increase in initiation between 2010 and 2011 was statistically significant (OR=4.38, 95\% CI: 3.13-6.12).

When we excluded provider recommendation from the multivariate model, additional variables became statistically significant (Table 3 ). HPV vaccine initiation was higher among sons who had visited their healthcare providers in the last year (OR=1.86, 95\% CI: 1.23-2.81), while initiation was lower among sons whose mothers had a high school education (compared to those whose mothers had less than a high school education; $\mathrm{OR}=0.66,95 \%$ CI: $0.45-0.97)$.

\section{Intent to Vaccinate and Reasons for Not Intending to Vaccinate}

Parents with unvaccinated sons reported relatively low levels of intent to vaccinate in the next year (mean $=2.45$, standard error $[\mathrm{SE}]=0.02$ ). Only $31.0 \%$ of these parents indicated their sons were "somewhat likely" or "very likely" to receive HPV vaccine in the next year. Over half (59.7\%) said their sons were "not too likely" or "not likely atall" to receive the vaccine in the next year, while $9.3 \%$ were not sure. Parents' intent to vaccinate their sons increased from 2010 (mean=2.37, $\mathrm{SE}=0.03)$ to 2011 (mean=2.54, $\mathrm{SE}=0.03)(p<0.001)$.

The most common main reasons for parents not intending to vaccinate in the next year were believing vaccination is not needed or not necessary $(24.5 \%)$, not having received a provider recommendation $(22.1 \%)$, lack of knowledge $(15.9 \%)$, son not being sexually active (14.7\%), child being male (12.0\%), and concerns about vaccine safety or side effects (5.6\%) (Table 4). All other reasons were reported by less than $5.0 \%$ of parents.

\section{Discussion}

Less than $10 \%$ of adolescent males had received any doses of HPV vaccine within the first years following vaccine licensure for males. Although HPV vaccine initiation increased from 2010 to 2011, initiation was still much lower than what was observed among adolescent females in the US following vaccine licensure for them. Initiation among adolescent females was about 25\% within the first year following licensure (2007) and over $30 \%$ by the end of the second year (2008) [34-37]. As discussed previously [16], this gender difference is likely due in part to the ACIP providing different initial recommendations for vaccination. The ACIP first provided a permissive recommendation for males [8], while providing the stronger recommendation for routine administration for females [38]. The ACIP replaced the permissive recommendation and began recommending routine HPV vaccination for males in October 2011 [9]. Since data collection for the current study occurred primarily when the permissive recommendation was in place, our results suggest that the permissive recommendation did not raise vaccine coverage to the extent that the recommendation for routine provision did for females. Continued surveillance will be important to monitor the effects of the updated recommendation and any associated changes in insurance coverage of the vaccine, which may lead to increased vaccine access for males.

Even though the updated recommendation will likely improve HPV vaccine uptake among males, guidelines alone are likely insufficient to achieve widespread vaccine uptake (similar to what has been observed among US females [15]). Therefore, additional intervention strategies will be critically important. One promising intervention strategy will be to increase healthcare providers' recommendations to vaccinate [39]. Similar to past research $[16,26]$, provider recommendation was the strongest correlate of HPV vaccine initiation and lack of provider recommendation was among the most common reasons for not intending to vaccinate. Only about $10 \%$ of parents in the current study had received a provider 
recommendation, which may be partly attributable to healthcare providers being unsure about the permissive recommendation and insurance coverage of the vaccine under this recommendation [40]. However, over $80 \%$ of sons had visited a healthcare provider in the last year, indicating there are many opportunities for provider recommendations to occur. Visiting a healthcare provider in the last year was also associated with HPV vaccine initiation, but only in the multivariate model that excluded provider recommendation. Interventions targeting healthcare providers can help ensure that recommendations are occurring during healthcare visits. Future studies are needed to determine how the updated recommendation for routine vaccination and other intervention strategies affect provider recommendation of HPV vaccine for males.

Efforts are also needed to educate parents and sons about the availability of and need for vaccinating males against HPV. Research has shown that only about $20 \%$ of parents and $10 \%$ of sons are aware that HPV vaccine can be given to males [14], and our study suggests that lack of knowledge continues to be problematic. Many of the most common reasons for parents not intending to vaccinate involved a perceived lack of knowledge about HPV vaccine or not recognizing the need to vaccinate males. For this reason, increasing parents' and sons' understanding of the importance of HPV vaccine for males is important.

Although HPV vaccination was low overall among adolescent males in the current study, some findings on health disparities were encouraging. Specifically, initiation was higher among sons who were Hispanic or eligible for the VFC program. Hispanic males are more likely to be infected with multiple HPV types compared to non-Hispanic whites [41], while Hispanic females have the highest cervical cancer incidence rate of any racial or ethnic group in the US [42]. Vaccinating Hispanics against HPV can therefore have a substantial public health impact, and our results provide evidence that vaccination is higher among Hispanic males. This pattern is similar to past studies examining HPV vaccination among adolescent females and males $[13,15]$. Our findings also suggest that the VFC Program has been successful thus far in providing access to HPV vaccine for adolescent males. HPV vaccine is one of the most expensive vaccines (about $\$ 130$ per dose [43]), so it is important that the VFC program is effective in reaching underserved populations. Our results concerning the VFC program may be partly due to the permissive recommendation, under which the VFC program covered HPV vaccine for males but some private health insurance plansdid not[10]. Furthermore, some immunization programs supplied HPV vaccine to providers specifically to vaccinate VFC-eligible and other underinsured children [40]. Healthcare providers may have thereforebeen less inclinedto vaccinate males with private health insurance.

Parents with unvaccinated sons reported relatively low levels of intent to vaccinate in the next year, with only about $30 \%$ indicating intent. This estimate is lower than those from studies conducted prior to or just after the vaccine was first recommended for males [1820], when vaccination may have seemed somewhat hypothetical to parents. Our finding is, however, similar to results from a recent longitudinal study [16]. It is worth noting that parents' intent to vaccinate did increase from 2010 to 2011, which differs from the recent longitudinal study that found vaccine acceptability among parents decreased over time [16]. This inconsistency could be due to a difference in study designs. The NIS-Teen is a serial cross-sectional survey with an independent sample for each year, whereas the longitudinal study surveyed the same participants at two timepoints [16]. It remains important to continue to monitor how parents' intent to vaccinate their sons against HPV may be changing over time.

Study strengths include HPV vaccination data based on healthcare provider records for a large, nationally representative sample of adolescent males. Study limitations include 
differing RDD sampling frame approaches for 2010 and 2011 and household response rates below $60 \%$. Some parents may have incorrectly recalled whether they had ever received a provider recommendation to get their sons HPV vaccine. We did not examine correlates of HPV vaccine completion because so few sons had received all three recommended doses. It is possible that healthcare provider vaccination records might be incomplete, and the NISTeen did not examine some factors potentially important to HPV vaccine initiation (e.g., parents' health beliefs $[44,45])$.

\section{Conclusions}

HPV vaccine uptake among males was low under the permissive recommendation first provided for males. Even with the recommendation for routine vaccination of males now in place, additional intervention strategies will likely still be needed to achieve widespread HPV vaccine uptake among males. Healthcare providers are a key target for such interventions, given the importance of provider recommendation to HPV vaccination behaviors. Future efforts are needed to determine how the updated recommendation, potential changes in health insurance coverage of the vaccine for males, and other intervention strategies affect HPV vaccine uptake among males.

\section{Acknowledgments}

Support provided by the National Institutes of Health (P50CA105632 and P30CA016058) and the Cancer Control Education Program at UNC Lineberger Comprehensive Cancer Center (R25CA57726). Data for the NIS-Teen are collected and managed by the Centers for Disease Prevention and Control (National Center for Health Statistics and the National Center for Immunization and Respiratory Diseases). The findings and conclusions in this paper are those of the authors and do not necessarily represent the views of these organizations.

\section{References}

1. U.S. Food and Drug Administration. Gardasil. 2010. Available at: http://www.fda.gov/ BiologicsBloodVaccines/Vaccines/ApprovedProducts/ucm094042.htm

2. Lacey CJ, Lowndes CM, Shah KV. Chapter 4: Burden and management of non-cancerous HPVrelated conditions: HPV-6/11 disease. Vaccine. 2006; 24(Suppl 3):S3/35-41. [PubMed: 16950016]

3. Hoots BE, Palefsky JM, Pimenta JM, Smith JS. Human papillomavirus type distribution in anal cancer and anal intraepithelial lesions. Int J Cancer. 2009; 124(10):2375-83. [PubMed: 19189402]

4. Dinh TH, Sternberg M, Dunne EF, Markowitz LE. Genital warts among 18- to 59-year-olds in the United States, National Health and Nutrition Examination Survey, 1999--2004. Sex Transm Dis. 2008; 35(4):357-60. [PubMed: 18360316]

5. American Cancer Society. Cancer Facts \& Figures 2013. Atlanta: American Cancer Society; 2012.

6. Elbasha EH, Dasbach EJ. Impact of vaccinating boys and men against HPV in the United States. Vaccine. 2010; 28(42):6858-67. [PubMed: 20713101]

7. Reiter PL, Pendergraft WF 3rd, Brewer NT. Meta-analysis of human papillomavirus infection concordance. Cancer Epidemiol Biomarkers Prev. 2010; 19(11):2916-31. [PubMed: 20833971]

8. Centers for Disease Control and Prevention. FDA licensure of quadrivalent human papillomavirus vaccine (HPV4, Gardasil) for use in males and guidance from the Advisory Committee on Immunization Practices (ACIP). MMWR Morb Mortal Wkly Rep. 2010; 59(20):630-2. [PubMed: 20508594]

9. Centers for Disease Control and Prevention (CDC). Recommendations on the use of quadrivalent human papillomavirus vaccine in males--Advisory Committee on Immunization Practices (ACIP), 2011. MMWR Morb Mortal Wkly Rep. 2011; 60(50):1705-8. [PubMed: 22189893]

10. Haupt, RM.; Sylvester, GC. HPV disease in males and vaccination: Implications and opportunities for pediatricians. Infectious Diseases in Children. 2010. Available at: http:// www.pediatricsupersite.com/view.aspx?rid=66396 
11. Centers for Disease Control and Prevention. Vaccines for Children Program (VFC). 2013. Available at: http://www.cdc.gov/vaccines/programs/vfc/index.html

12. Centers for Disease Control and Prevention. National and state vaccination coverage among adolescents aged 13 through 17 years --- United States, 2010. MMWR Morb Mortal Wkly Rep. 2011; 60:1117-23. [PubMed: 21866084]

13. Laz TH, Rahman M, Berenson AB. Human papillomavirus vaccine uptake among 9-17 year old males in the United States: The National Health Interview Survey, 2010. Hum Vaccin Immunother. 2013; 9(4)

14. Reiter PL, McRee AL, Kadis JA, Brewer NT. HPV vaccine and adolescent males. Vaccine. 2011; 29(34):5595-602. [PubMed: 21704104]

15. Centers for Disease Control and Prevention (CDC). National and state vaccination coverage among adolescents aged 13-17 years - United States, 2011. MMWR Morb Mortal Wkly Rep. 2012; 61:671-7. [PubMed: 22932301]

16. Reiter PL, McRee AL, Pepper JK, Gilkey MB, Galbraith KV, Brewer NT. Longitudinal predictors of HPV vaccination among a national sample of adolescent males. American Journal of Public Health. (In press).

17. Kessels SJ, Marshall HS, Watson M, Braunack-Mayer AJ, Reuzel R, Tooher RL. Factors associated with HPV vaccine uptake in teenage girls: A systematic review. Vaccine. 2012; 30(24): 3546-56. [PubMed: 22480928]

18. Reiter PL, McRee AL, Gottlieb SL, Brewer NT. HPV vaccine for adolescent males: acceptability to parents post-vaccine licensure. Vaccine. 2010; 28(38):6292-7. [PubMed: 20637770]

19. Liddon N, Hood J, Wynn BA, Markowitz LE. Acceptability of human papillomavirus vaccine for males: a review of the literature. J Adolesc Health. 2010; 46(2):113-23. [PubMed: 20113917]

20. Dempsey AF, Butchart A, Singer D, Clark S, Davis M. Factors associated with parental intentions for male human papillomavirus vaccination: results of a national survey. Sex Transm Dis. 2011; 38(8):769-76. [PubMed: 21336230]

21. Daley EM, Marhefka S, Buhi E, Hernandez ND, Chandler R, Vamos C, et al. Ethnic and racial differences in HPV knowledge and vaccine intentions among men receiving HPV test results. Vaccine. 2011; 29(23):4013-8. [PubMed: 21459176]

22. Hernandez BY, Wilkens LR, Thompson PJ, Shvetsov YB, Goodman MT, Ning L, et al. Acceptability of prophylactic human papillomavirus vaccination among adult men. Hum Vaccin. 2010; 6(6):467-75. [PubMed: 20671442]

23. Reiter PL, Brewer NT, McRee AL, Gilbert P, Smith JS. Acceptability of HPV vaccine among a national sample of gay and bisexual men. Sex Transm Dis. 2010; 37(3):197-203. [PubMed: 20118831]

24. Reiter PL, Brewer NT, Smith JS. Human papillomavirus knowledge and vaccine acceptability among a national sample of heterosexual men. Sex Transm Infect. 2010; 86(3):241-6. [PubMed: 19951936]

25. Wheldon CW, Daley EM, Buhi ER, Nyitray AG, Giuliano AR. Health beliefs and attitudes associated with HPV vaccine intention among young gay and bisexual men in the southeastern United States. Vaccine. 2011; 29(45):8060-5. [PubMed: 21864615]

26. Gilkey MB, Moss JL, McRee AL, Brewer NT. Do correlates of HPV vaccine initiation differ between adolescent boys and girls? Vaccine. 2012; 30(41):5928-34. [PubMed: 22841973]

27. Perkins RB, Apte G, Marquez C, Porter C, Belizaire M, Clark JA, et al. Factors affecting human papillomavirus vaccine use among White, Black and Latino parents of sons. Pediatr Infect Dis J. 2013; 32(1):e38-44. [PubMed: 22914585]

28. U.S. Department of Health and Human Services (DHHS). National Center for Health Statistics. The 2010 National Immunization Survey - Teen. Hyattsville, MD: Centers for Disease Control and Prevention; 2011.

29. U.S. Department of Health and Human Services (DHHS). National Center for Health Statistics. The 2011 National Immunization Survey - Teen. Hyattsville, MD: Centers for Disease Control and Prevention; 2012. 
30. Jain N, Singleton JA, Montgomery M, Skalland B. Determining accurate vaccination coverage rates for adolescents: the National Immunization Survey-Teen 2006. Public Health Rep. 2009; 124(5):642-51. [PubMed: 19753942]

31. Centers for Disease Control and Prevention, National Center for Immunization and Respiratory Diseases, National Center for Health Statistics. National Immunization Survey-Teen. A user's guide for the 2010 public-use data file. 2011. Available at: ftp://ftp.cdc.gov/pub/Health_Statistics/ NCHS/Dataset_Documentation/NIS/NISteenPUF10_DUG.pdf

32. Centers for Disease Control and Prevention, National Center for Immunization and Respiratory Diseases, National Center for Health Statistics. National Immunization Survey-Teen. A user's guide for the 2011 public-use data file. 2012. Available at: ftp://ftp.cdc.gov/pub/Health_Statistics/ NCHS/Dataset_Documentation/NIS/NISteenPUF11_DUG.pdf

33. Gierisch JM, Reiter PL, Rimer BK, Brewer NT. Standard definitions of adherence for infrequent yet repeated health behaviors. Am J Health Behav. 2010; 34(6):669-79. [PubMed: 20604693]

34. Dorell CG, Yankey D, Santibanez TA, Markowitz LE. Human papillomavirus vaccination series initiation and completion, 2008-2009. Pediatrics. 2011; 128(5):830-9. [PubMed: 22007006]

35. Centers for Disease Control and Prevention (CDC). Vaccination coverage among adolescents aged 13-17 years - United States, 2007. MMWR Morb Mortal Wkly Rep. 2008; 57(40):1100-3. [PubMed: 18846032]

36. Centers for Disease Control and Prevention (CDC). National, state, and local area vaccination coverage among adolescents aged 13-17 years--United States, 2008. MMWR Morb Mortal Wkly Rep. 2009; 58(36):997-1001. [PubMed: 19763075]

37. Reiter PL, Cates JR, McRee AL, Gottlieb SL, Shafer A, Smith JS, et al. Statewide HPV vaccine initiation among adolescent females in North Carolina. Sex Transm Dis. 2010; 37(9):549-56. [PubMed: 20414146]

38. Markowitz LE, Dunne EF, Saraiya M, Lawson HW, Chesson H, Unger ER, et al. Quadrivalent Human Papillomavirus Vaccine: Recommendations of the Advisory Committee on Immunization Practices (ACIP). MMWR Recomm Rep. 2007; 56(RR-2):1-24. [PubMed: 17380109]

39. Stupiansky NW, Alexander AB, Zimet GD. Human papillomavirus vaccine and men: what are the obstacles and challenges? Curr Opin Infect Dis. 2012; 25(1):86-91. [PubMed: 22143118]

40. Wells, K.; Zucker, JR.; Hannan, C. The impact of ACIP HPV vaccine permissive recommendation on state, local and territorial immunization programs. Presented at the National Immunization Conference; Washington, DC. 2011. Available at: http://www.immunizationmanagers.org/ presentations_research/survey_docs/12.pdf

41. Nielson CM, Harris RB, Flores R, Abrahamsen M, Papenfuss MR, Dunne EF, et al. Multiple-type human papillomavirus infection in male anogenital sites: prevalence and associated factors. Cancer Epidemiol Biomarkers Prev. 2009; 18(4):1077-83. [PubMed: 19318438]

42. Watson M, Saraiya M, Benard V, Coughlin SS, Flowers L, Cokkinides V, et al. Burden of cervical cancer in the United States, 1998-2003. Cancer. 2008; 113(10 Suppl):2855-64. [PubMed: 18980204]

43. Centers for Disease Control and Prevention. CDC vaccine price list. 2012. Available at: http:// www.cdc.gov/vaccines/programs/vfc/awardees/vaccine-management/price-list/index.html

44. Reiter PL, Brewer NT, Gottlieb SL, McRee AL, Smith JS. Parents' health beliefs and HPV vaccination of their adolescent daughters. Soc Sci Med. 2009; 69(3):475-480. [PubMed: 19540642]

45. Brewer NT, Gottlieb SL, Reiter PL, McRee AL, Liddon N, Markowitz L, et al. Longitudinal predictors of human papillomavirus vaccine initiation among adolescent girls in a high-risk geographic area. Sex Transm Dis. 2011; 38(3):197-204. [PubMed: 20838362] 


\section{Highlights}

- HPV vaccination is low among adolescent males, with less than $10 \%$ vaccinated

- Healthcare provider recommendation is key to increasing HPV vaccination among males

- Continued efforts are needed to monitor HPV vaccination among males 
Table 1

Characteristics of parents and adolescent sons, 2010-2011 National Immunization Survey-Teen $(n=22,365)$

\begin{tabular}{|c|c|}
\hline & n (weighted \%) \\
\hline \multicolumn{2}{|l|}{ Year } \\
\hline 2010 & 10037 (49.6) \\
\hline 2011 & $12328(50.4)$ \\
\hline \multicolumn{2}{|l|}{ Son characteristics } \\
\hline \multicolumn{2}{|l|}{ Age } \\
\hline $13 \mathrm{yr}$ & $4573(19.4)$ \\
\hline $14 \mathrm{yr}$ & $4582(19.7)$ \\
\hline $15 \mathrm{yr}$ & $4488(20.8)$ \\
\hline $16 \mathrm{yr}$ & $4584(21.1)$ \\
\hline $17 \mathrm{yr}$ & $4138(19.1)$ \\
\hline \multicolumn{2}{|l|}{ Race/ethnicity } \\
\hline White, non-Hispanic & $15346(58.6)$ \\
\hline Black, non-Hispanic & $2267(14.4)$ \\
\hline Other, non-Hispanic & $1835(7.7)$ \\
\hline Hispanic & $2917(19.3)$ \\
\hline \multicolumn{2}{|l|}{ Visited healthcare provider in last year } \\
\hline No & $3543(19.0)$ \\
\hline Yes & $18690(81.0)$ \\
\hline \multicolumn{2}{|l|}{ Healthcare coverage } \\
\hline Through parent employer or union & $14940(59.0)$ \\
\hline Other insurance, including Medicaid & $6102(33.9)$ \\
\hline No insurance & $1183(7.1)$ \\
\hline \multicolumn{2}{|l|}{ Eligible for VFC Program } \\
\hline No & $15674(63.2)$ \\
\hline Yes & $6640(36.8)$ \\
\hline \multicolumn{2}{|l|}{ Parent characteristics } \\
\hline \multicolumn{2}{|l|}{ Mother's age } \\
\hline$<35 \mathrm{yr}$ & $1611(9.3)$ \\
\hline $35-44$ yr & $9280(45.0)$ \\
\hline $45+\mathrm{yr}$ & $11474(45.7)$ \\
\hline \multicolumn{2}{|l|}{ Mother's education } \\
\hline Less than high school & $2028(13.4)$ \\
\hline High school & $4542(26.6)$ \\
\hline Some college & $6228(25.5)$ \\
\hline College graduate & $9567(34.5)$ \\
\hline \multicolumn{2}{|l|}{ Mother's marital status } \\
\hline Not married & $5380(29.8)$ \\
\hline Married & $16985(70.2)$ \\
\hline Heard of HPV ${ }^{a}$ & \\
\hline
\end{tabular}




\begin{tabular}{lc}
\hline & n (weighted \%) \\
\hline No & $3953(21.2)$ \\
Yes & $18030(78.8)$ \\
Heard of HPV vaccine ${ }^{a}$ & \\
No & $2994(18.0)$ \\
Yes & $19128(82.0)$ \\
Received provider recommendation to get son HPV vaccine \\
No & $19275(90.1)$ \\
Yes & $2381(9.9)$ \\
Household characteristics & \\
Poverty status & \\
Below poverty & $3184(21.7)$ \\
Above poverty, $<\$ 75,000$ & $8802(42.4)$ \\
Above poverty, $>\$ 75,000$ & $9494(35.9)$ \\
\hline
\end{tabular}

Note. Totals may not sum to stated sample size due to missing data. Percents may not sum to $100 \%$ due to rounding. HPV=human papillomavirus; $\mathrm{VFC}=\mathrm{Vaccines}$ for Children.

${ }^{a}$ Among only parents with unvaccinated sons, $78.5 \%$ had heard of HPV and $81.7 \%$ had heard of HPV vaccine. 
Table 2

HPV vaccination among adolescent males, 2010-2011 National Immunization Survey-Teen $(n=22,365)$

\begin{tabular}{|c|c|c|}
\hline & No. Initiated HPV Vaccine Regimen / Total No. in Category (\%) & Bivariate OR $(95 \% \mathrm{CI})$ \\
\hline Overall & $1214 / 22365(4.9)$ & -- \\
\hline \multicolumn{3}{|l|}{ Year } \\
\hline 2010 & $169 / 10037(1.4)$ & ref. \\
\hline 2011 & $1045 / 12328(8.3)$ & $6.45(4.81-8.66)^{* *}$ \\
\hline \multicolumn{3}{|l|}{ Son characteristics } \\
\hline \multicolumn{3}{|l|}{ Age } \\
\hline $13 \mathrm{yr}$ & 250/4573 (5.6) & ref. \\
\hline $14 \mathrm{yr}$ & $244 / 4582(4.7)$ & $0.84(0.60-1.19)$ \\
\hline $15 \mathrm{yr}$ & $250 / 4488(4.5)$ & $0.81(0.58-1.12)$ \\
\hline $16 \mathrm{yr}$ & $243 / 4584(5.5)$ & $0.99(0.67-1.45)$ \\
\hline $17 \mathrm{yr}$ & $227 / 4138(3.9)$ & $0.69(0.49-0.96)^{*}$ \\
\hline \multicolumn{3}{|l|}{ Race/ethnicity } \\
\hline White, non-Hispanic & $627 / 15346(3.3)$ & ref. \\
\hline Black, non-Hispanic & $160 / 2267(5.8)$ & $1.78(1.34-2.37)^{* * *}$ \\
\hline Other, non-Hispanic & $100 / 1835(5.1)$ & $1.56(1.07-2.27)^{*}$ \\
\hline Hispanic & $327 / 2917(8.8)$ & $2.81(2.11-3.74)^{* *}$ \\
\hline \multicolumn{3}{|l|}{ Visited healthcare provider in last year } \\
\hline No & $112 / 3543(3.0)$ & ref. \\
\hline Yes & $1087 / 18690(5.3)$ & $1.82(1.26-2.63)^{*}$ \\
\hline \multicolumn{3}{|l|}{ Healthcare coverage } \\
\hline Through parent employer or union & $657 / 14940(3.1)$ & ref. \\
\hline Other insurance, including Medicaid & $506 / 6102(8.2)$ & $2.75(2.21-3.43))^{* *}$ \\
\hline No insurance & $43 / 1183(3.5)$ & $1.11(0.57-2.19)$ \\
\hline \multicolumn{3}{|l|}{ Eligible for VFC Program } \\
\hline No & $670 / 15674(3.2)$ & ref. \\
\hline Yes & $542 / 6640(7.8)$ & $2.57(2.06-3.21)^{* *}$ \\
\hline \multicolumn{3}{|l|}{ Parent characteristics } \\
\hline \multicolumn{3}{|l|}{ Mother's age } \\
\hline$<35 \mathrm{yr}$ & $135 / 1476(8.0)$ & ref. \\
\hline $35-44 \mathrm{yr}$ & $556 / 9280(5.1)$ & $0.62(0.44-0.89)^{*}$ \\
\hline $45+\mathrm{yr}$ & $523 / 11474(3.9)$ & $0.47(0.32-0.69)^{* *}$ \\
\hline \multicolumn{3}{|l|}{ Mother's education } \\
\hline Less than high school & 206/2028 (9.2) & ref. \\
\hline High school & $261 / 4542(4.5)$ & $0.47(0.33-0.67)^{* * *}$ \\
\hline Some college & $309 / 6228(5.2)$ & $0.55(0.38-0.79)^{*}$ \\
\hline College graduate & $438 / 9567(3.2)$ & $0.33(0.23-0.47)^{* *}$ \\
\hline
\end{tabular}




\begin{tabular}{|c|c|c|}
\hline & No. Initiated HPV Vaccine Regimen / Total No. in Category (\%) & Bivariate OR ( $95 \%$ CI) \\
\hline Not married & $391 / 5380(6.3)$ & ref. \\
\hline Married & $823 / 16985(4.2)$ & $0.66(0.52-0.83)^{* *}$ \\
\hline \multicolumn{3}{|c|}{ Received provider recommendation for HPV vaccine } \\
\hline No & $361 / 19275(2.0)$ & ref. \\
\hline Yes & $808 / 2381(30.8)$ & $21.86(16.95-28.19)^{* *}$ \\
\hline \multicolumn{3}{|l|}{ Household characteristics } \\
\hline \multicolumn{3}{|l|}{ Poverty status } \\
\hline Below poverty & $307 / 3184(8.9)$ & ref. \\
\hline Above poverty, $<\$ 75,000$ & $436 / 8802(4.8)$ & $0.51(0.39-0.68)^{* *}$ \\
\hline Above poverty, $>\$ 75,000$ & $423 / 9494(2.8)$ & $0.30(0.22-0.40)^{* *}$ \\
\hline
\end{tabular}

Note. $\mathrm{HPV}=$ human papillomavirus, No. = number, $\mathrm{OR}=$ odds ratio, $\mathrm{CI}=$ confidence interval, ref. $=$ referent group, VFC=Vaccines for Children. Totals may not sum to stated sample size due to missing data.

* $p<0.05$,

*** $p<0.001$ 
Table 3

Multivariate models for HPV vaccination among adolescent males, 2010-2011 National Immunization Survey-Teen

\begin{tabular}{|c|c|c|}
\hline & Full Model OR (95\% CI) & Excluding Provider Recommendation OR (95\% CI) \\
\hline \multicolumn{3}{|l|}{ Year } \\
\hline 2010 & ref. & ref. \\
\hline 2011 & $4.38(3.13-6.12)^{* *}$ & $6.21(4.55-8.46)^{* *}$ \\
\hline \multicolumn{3}{|l|}{ Son characteristics } \\
\hline \multicolumn{3}{|l|}{ Age } \\
\hline $13 \mathrm{yr}$ & ref. & ref. \\
\hline $14 \mathrm{yr}$ & $0.76(0.48-1.22)$ & $0.77(0.54-1.12)$ \\
\hline $15 \mathrm{yr}$ & $0.95(0.62-1.46)$ & $0.80(0.57-1.14)$ \\
\hline $16 \mathrm{yr}$ & $0.89(0.57-1.40)$ & $0.93(0.64-1.36)$ \\
\hline $17 \mathrm{yr}$ & $0.90(0.58-1.38)$ & $0.73(0.51-1.05)$ \\
\hline \multicolumn{3}{|l|}{ Race/ethnicity } \\
\hline White, non-Hispanic & ref. & ref. \\
\hline Black, non-Hispanic & $1.26(0.86-1.86)$ & $1.22(0.85-1.75)$ \\
\hline Other, non-Hispanic & $0.97(0.59-1.61)$ & $1.07(0.68-1.68)$ \\
\hline Hispanic & $1.83(1.24-2.71)^{*}$ & $1.90(1.36-2.65)^{* * *}$ \\
\hline \multicolumn{3}{|l|}{ Visited healthcare provider in last year } \\
\hline No & ref. & ref. \\
\hline Yes & $1.64(0.98-2.74)$ & $1.86(1.23-2.81)^{*}$ \\
\hline \multicolumn{3}{|l|}{ Healthcare coverage } \\
\hline Through parent employer or union & ref. & ref. \\
\hline Other insurance, including Medicaid & $1.61(1.08-2.40)^{*}$ & $1.59(1.12-2.25)^{*}$ \\
\hline No insurance & $0.81(0.34-1.93)$ & $0.64(0.31-1.31)$ \\
\hline \multicolumn{3}{|l|}{ Eligible for VFC Program } \\
\hline No & ref. & ref. \\
\hline Yes & $1.53(1.01-2.31)^{*}$ & $1.48(1.05-2.08)^{*}$ \\
\hline \multicolumn{3}{|l|}{ Parent characteristics } \\
\hline \multicolumn{3}{|l|}{ Mother's age } \\
\hline$<35 \mathrm{yr}$ & ref. & ref. \\
\hline $35-44 \mathrm{yr}$ & $0.80(0.50-1.28)$ & $0.88(0.59-1.31)$ \\
\hline $45+y r$ & $0.91(0.56-1.47)$ & $0.94(0.61-1.44)$ \\
\hline \multicolumn{3}{|l|}{ Mother's education } \\
\hline Less than high school & ref. & ref. \\
\hline High school & $0.71(0.43-1.17)$ & $0.66(0.45-0.97)^{*}$ \\
\hline Some college & $0.90(0.52-1.55)$ & $0.91(0.60-1.36)$ \\
\hline College graduate & $0.78(0.44-1.37)$ & $0.77(0.49-1.22)$ \\
\hline \multicolumn{3}{|l|}{ Mother's marital status } \\
\hline Not married & ref. & ref. \\
\hline
\end{tabular}




\begin{tabular}{|c|c|c|}
\hline & Full Model OR (95\% CI) & Excluding Provider Recommendation OR $(95 \%$ CI $)$ \\
\hline Married & $1.00(0.71-1.40)$ & $1.06(0.79-1.41)$ \\
\hline \multicolumn{3}{|c|}{ Received provider recommendation for HPV vaccine } \\
\hline No & ref. & -- \\
\hline Yes & $19.02(14.36-25.19)^{* *}$ & -- \\
\hline \multicolumn{3}{|l|}{ Household characteristics } \\
\hline \multicolumn{3}{|l|}{ Poverty status } \\
\hline Below poverty & ref. & ref. \\
\hline Above poverty, $<\$ 75,000$ & $0.93(0.60-1.43)$ & $0.89(0.63-1.25)$ \\
\hline Above poverty, $>\$ 75,000$ & $0.63(0.36-1.11)$ & $0.71(0.44-1.16)$ \\
\hline
\end{tabular}

Note. HPV = human papillomavirus, $\mathrm{OR}=$ odds ratio, $\mathrm{CI}=$ confidence interval, ref. = referent group, VFC=Vaccines for Children. Dashes (--) indicate that variable was not included in multivariate model. Multivariate models controlled for state of residence. Due to missing data for potential correlates, full model included data on 20,603 adolescent malesand model excluding provider recommendation included 21,193 adolescent males.

$*$
$p<0.05$,
$* *$

*** $p<0.001$ 
Table 4

Main reasons why parents did not intend to get their adolescent sons HPV vaccine in the next year $(n=14,003)$

\begin{tabular}{lc}
\hline & n (weighted \%) \\
\hline Vaccination not needed or not necessary for son & $3390(24.5)$ \\
Did not receive healthcare provider recommendation & $3039(22.1)$ \\
Lack of knowledge & $2058(15.9)$ \\
Son not sexually active & $2141(14.7)$ \\
Child is male & $1806(12.0)$ \\
Vaccine safety concern/side effects & $801(5.6)$ \\
Son not appropriate age & $638(4.2)$ \\
Costs & $206(1.7)$ \\
No doctor or doctor's visit not scheduled & $188(1.4)$ \\
Family/parent decision & $184(1.1)$ \\
Not a school requirement & $118(1.1)$ \\
Need more information/new vaccine & $140(1.0)$ \\
Son should make decision & $89(0.7)$ \\
Son fearful & $101(0.6)$ \\
Don't believe in vaccinations & $56(0.5)$ \\
Son handicapped/special needs/illness & $66(0.4)$ \\
Vaccine not available & $26(0.1)$ \\
Religious beliefs/orthodox & $25(0.1)$ \\
Son's vaccines already up to date & $18(0.1)$ \\
Vaccine effectiveness concern & $14(0.1)$ \\
Increased sexual activity concern & $14(0.1)$ \\
Son will get vaccinated as part of college entry requirements & $10(0.1)$ \\
\hline & $4(<0.1)$ \\
& $2(<0.1)$ \\
Other reason & $201(1.4)$ \\
\hline
\end{tabular}

Note. HPV = human papillomavirus. Table includes parents of unvaccinated sons who indicated they were "not likely at all," "not too likely," or "not sure/don't know" about getting their sons HPV vaccine in the next year. 